\title{
Correction to: How can clinicians, specialty societies and others evaluate and improve the quality of apps for patient use?
}

Jeremy C. Wyatt

\section{Correction to: BMC Med https://doi.org/10.1186/s12916-018-1211-7}

Since the publication of this article [1] it has come to my attention that it contains an error in which the y-axis in Fig. 2 was inverted, thus incorrectly displaying a weak negative correlation rather than a weak positive one. This error was introduced as the order of the data on which Fig. 2 was based [2] was misread. The corrected version of Fig. 2 can be seen below, in which a weak positive correlation is now displayed. This does not change the general point, that app users and app stores appear to take little notice of the source of information on which apps are based. I apologise to readers for this error.

Received: 26 June 2019 Accepted: 1 July 2019

Published online: 20 July 2019

\section{References}

1. Wyatt JC. How can clinicians, specialty societies and others evaluate and improve the quality of apps for patient use? BMC Med. 2018; https:// bmcmedicine.biomedcentral.com/articles/10.1186/s12916-018-1211-7.

2. Abroms LC, Lee Westmaas J, Bontemps-Jones J, Ramani R, Mellerson J. A content analysis of popular smartphone apps for smoking cessation. Am J Prev Med. 2013;45(6):732-6. https://doi.org/10.1016/j.amepre.2013.07.008.

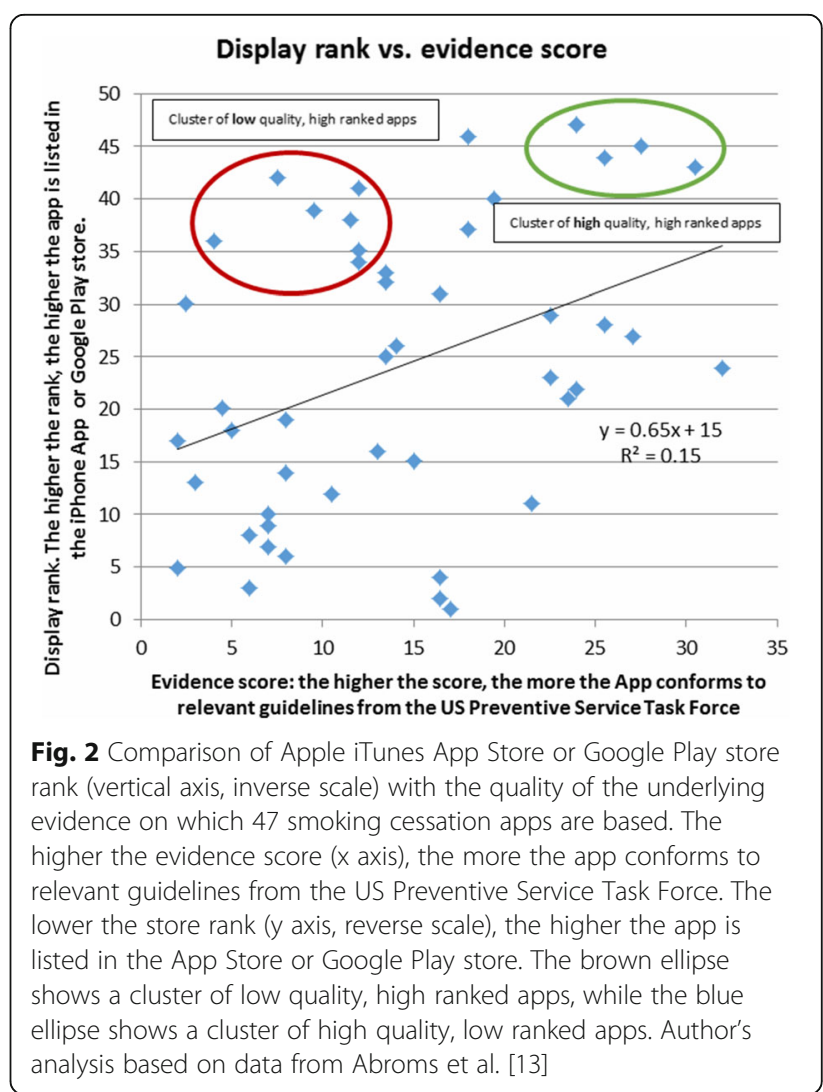

Correspondence: j.c.wyatt@soton.ac.uk

Wessex Institute of Health, Faculty of Medicine, University of Southampton Southampton SO16 7NS, UK

(C) The Author(s). 2019 Open Access This article is distributed under the terms of the Creative Commons Attribution 4.0 International License (http.//creativecommons.org/licenses/by/4.0/), which permits unrestricted use, distribution, and reproduction in any medium, provided you give appropriate credit to the original author(s) and the source, provide a link to the Creative Commons license, and indicate if changes were made. The Creative Commons Public Domain Dedication waiver (http://creativecommons.org/publicdomain/zero/1.0/) applies to the data made available in this article, unless otherwise stated. 